\title{
Betwixt, Between, Besides: Reflections on Moving Beyond the Binary in Reproductive Health Care
}

\author{
A.J. Lowik, PhD
}

\begin{abstract}
The objectives of this article are two-fold. First, it is a personal reflection on the need for reproductive health-care spaces and services where sex and gender binaries are challenged and room for non-binary people is made. Second, it is a critical commentary on why and how cis- and trans-normative understandings of sex and gender form the foundation of reproductive health care as it is currently delivered. Taken together, this article is a call to action for nurses to be creative in challenging sex and gender binaries in their provision of reproductive health care.
\end{abstract}

Keywords: transgender; non-binary; reproductive health; cis-normativity; trans-normativity

[Editor's Note: The italicized narrative prose interspersed throughout this article contains the author's own words, based on their personal experiences as a non-binary person struggling to navigate gendered reproductive health-care spaces.]

Am I both? Neither? A failed woman? A notquite man? Honestly, I'm still finding the language to articulate how I feel about myself in relation to the gender categories available to me. I am endlessly reaching for the gender "optout" button and experiencing equally endless distress when I find no such button there.

$A^{t}$ $t$ around the same time that I began questioning my gender, I was working in an abortion clinic - an incredible job that taught me so much about (in)equity, (in)justice, (com)passion, and resilience. Just as I started asking questions to and of myself about my own gender, so too did I start asking questions about my workplace: How would trans people experience the services we provide? What would trans-inclusion look like, in a space that has traditionally understood itself as being by and for (cis) women? What are the barriers and obstacles that trans people would experience if they needed to walk through a door marked (literally and metaphorically) with the word "Woman," if they identified not as women, but as something else? For over 15 years, I've been asking questions of my own gender, and as a researcher and trans-inclusion consultant, I've been asking questions of reproductive and sexual health-care spaces.

I am agender, I have no gender, I am just a person trying to be authentically myself amid a sea of checkboxes that don't fit, amid the pressures and expectations of others to land somewhere, anywhere intelligible. I am a non-binary trans person. An identity that defies classification in a two-sex/gender-binary system, built on foundations of colonialism, White supremacy, and Eurocentrism. A person who refuses to shore up cis-normativity in my life and in my work, both academic and in the community.

This is what I've learned, and why I am adamant that we need to move beyond the binary when it comes to how we research reproductive and sexual healthcare needs, as well as how we design and deliver services.

Western medical establishments as we know them were built to serve White, cisgender, heterosexual, able men. The system is not broken. It is doing exactly what it was designed to do. (Cis) women's health, the health of people of color, the health of queer folks, of disabled folks, of poor folks, have historically been ignored-and that is no accident. When (cis, White, able, straight) women entered post-secondary education, entered medical schools, entered the workforce, 
they made space for themselves. The women's hospital was born (Bueter, 2017). The free-standing abortion clinic, years later. These spaces and the services they offer were meant to fill a very real and devastating gap in our knowledge and in our delivery of health care. The body was no longer universally male-there were uniquely female corporeal and embodied experiences that were worthy of consideration (Grosz, 1994). Cisgender women have bodies, and those bodies have health-care needs, and the creation of women-centered health-care services emerged from this reality. Challenging androcentrism in medicine has been and continues to be incredibly vital work.

At the same time, however, the resulting gendered silos of health, including reproductive health specifically (and reproductive life, more generally) don't necessarily work for trans people. Not only women menstruate, have cervixes, get pregnant, lactatesome men do. Not only men produce sperm, have testicles and prostates-some women do. Trans people have (or ought to have access to) rich, reproductive lives, too. But the cis-normatively gendered silos we've created, a door marked women's health and another marked men's, don't work for trans people. Not only are we frequently expecting trans women to go through the door marked "Men" if they need a penile swab for sexually-transmitted and blood-borne infections (STBBI) testing, as well as expecting trans men to go through the door marked "Women" if they are giving birth, but there are all kinds of non-binary people-agender, gender neutral, genderqueer, neutrois, gender-fluid, plurigender, and countless more, not to mention intersex people, who simply have no door to walk through. There are others who are othered by these silos. What about their reproductive health needs?

And even when we do think about trans people, our experiences, identities, and narratives are typically understood through an ideology of trans-normativity (Johnson, 2016). That is, trans people are held accountable to a specific set of binary and medicalized standards, where what is at stake is being deemed "legitimate" in the eyes of the law, medical providers, and journalists, among others. Trans people who do not (or cannot) identity in binary ways and who do not (or cannot) adhere to a medical model of transition, have their very identities questioned, challenged, or outright rejected. We use cisgender people as the model of normalcy, against which we measure trans people.

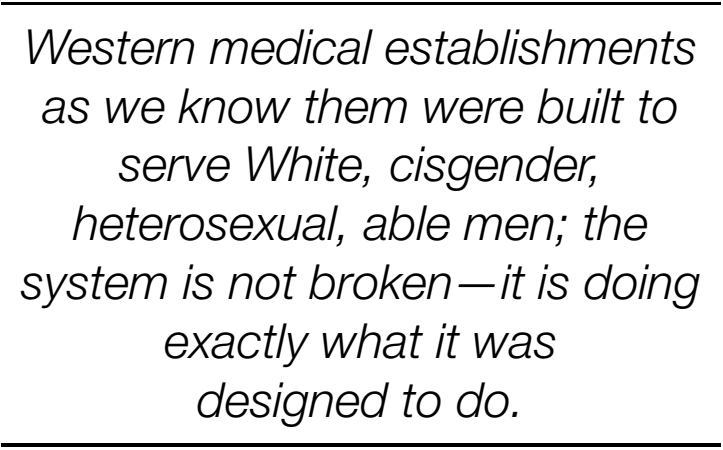

My dysphoria is not attached to this body. I am dysphoric because of how people incorrectly perceive and treat me because of this body. My dysphoria exists because my understanding of myself as being without gender makes no sense in this world, in this moment. There is no room for me. My body isn't wrong. The binary foundations of our language, along with the systems and structures that we've built that assume all people are cisgender, identify along the binary in cis-normative ways-that's what's wrong.

Reproductive life and decision-making are also caught up in this repressive, gatekeeping ideology. We expect trans people to adhere to a cis-normative "congruence" between gender identity, reproductive desires, and parenting roles. For example, if one is "truly" a man, it is reasoned, one ought to permanently and completely transition, both socially and medically, where the erasure of one gender, including reproductive capacity, is understood as necessary in order to take on another (von Doussa, Power, \& Riggs, 2015). Since men (cis-normatively speaking) do not have uteruses, vulvas, vaginas, do not get pregnant, do not give birth, do not lactate or nurse children, a trans-normative ideology would reason that trans men, as men, should also not have these body parts, should not engage in these embodied, reproductive experiences. A rejection of reproduction and reproductive failure in the form of infertility as a result of gender affirmation medical interventions are demanded as evidence of authentic trans identity (Surkan, 2013; Verlinden, 2012).

But of course, it's much more complicated than that. Trans people have reproductive desires, including desires that extend beyond the confines of the trans-normative narratives described above. Not only 
that, trans people are already parents, are already using their reproductive capacities in ways that do not neatly align with this narrative of "wrong body" distress and denunciation. A 2014 Ontario study found that $77.9 \%$ of trans people who were parents, were biological parents to their children (James-Abra et al., 2015). Trans people have reproductive lives-and as such, demand inclusive, competent, and evidenceinformed reproductive health care.

As part of my dissertation research, I conducted qualitative interviews and engaged 14 participants in a photography exercise focused on exploring their reproductive decision-making and health-care experiences in British Columbia. One of my participants described an experience of transition, gender, and reproduction not often told-for Riley (not their real name), a White, 30-something genderqueer person, it was by accessing testosterone that they became increasingly comfortable in their body, which made it possible for them to consider pregnancy, childbirth, and nursing as viable options; these embodied experiences were newly available only because of the room testosterone made for them outside of the cis-normative "womanhood" imposed upon them due to their female-assigned body. Rather than transition as a rejection of their sexed body, including its reproductive capacities, Riley indicated that only after having accessed testosterone did using their sexed body in reproductive ways become imaginable. Riley had no interest in being a pregnant and breastfeeding woman-but they could envision themselves as a pregnant person who will nurse their children, a future made possible due to their access to testosterone. Although the data analysis and writing of my dissertation has only just begun, I share this preliminary insight into this participant's life here, because it beautifully illustrates the point-beyond-the-binary thinking is necessary, if health-care providers hope to provide someone like Riley with the kind of care they need and deserve.

Being misgendered is a part of my daily existence. Even after delivering a lecture or facilitating a workshop on trans-inclusion, members of the audience will misgender me without realizing the impact of what they've done.

Beyond-the-binary reproductive health-care delivery necessitates creativity, thinking outside of the boxes of female $=$ woman, male $=$ man. I recently gave a talk to the North Island College nursing program in Courtney, British Columbia. I was in awe of the nursing students I met there, along with the faculty and deans. They were hungry for the skills, tools,

Cisgender women have bodies,
and those bodies have
health-care needs, and the
creation of women-centered
health-care services emerged
from this reality; however, the
cis-normatively gendered silos of
health care don't necessarily
work for trans people.

and language of trans-inclusion, eager to learn how they could do better by their current and future trans patients, willing to have their assumptions questioned and their knowledge expanded. I left feeling optimistic that nurses are up for the challenge of creating transinclusive services and spaces, in reproductive health and beyond.

I enter the local women's hospital for my appointment-knowing that I need the $O B /$ GYN services offered inside, but skeptical as to what kind of care I would receive as a non-binary person in this gendered space. As a researcher who studies trans-inclusion in reproductive health care, I am always a bit skeptical. I carry the stories that others have shared with me into every appointment, along with my own collection of "that-never-shouldhave-happened" tales. But I am also hopeful, as every day I am meeting (and oftentimes training) providers who are open to doing better.

To my surprise and delight, both the studentin-training who is on site that day and the doctor are receptive, informed. They apologize for the gendered hoops I have had to jump through to get the appointment, for the lack of gender-neutral bathrooms, for the language of "woman" plastered on every pamphlet, every poster. I explain my symptoms, I ask for my options, I receive a prescription for a treatment I had never heard of before-one I am hopeful will work.

I am grateful for the compassion and knowledge of these providers-but still dismayed that their apologies are necessary. I accept their apologies (excuses?), grin and bear it in the women's washroom, 


\section{What I wish for, what I long for, what I'm working on creating, are services and spaces where people like me are not the exception to the rule, the guinea pig, the freak, the problem.}

mentally cross out "woman" and substitute "person" on every pamphlet they hand me.

But what I wish for, what I long for, what I'm working on creating, are services and spaces where apologies are not necessary, because people like me are not the exception to the rule, the guinea pig, the freak, the problem. What would reproductive life and health look like for me-but more importantly, for trans people of color; for Two-Spirit people; for folks who describe their genders in languages other than English; for disabled, poor, or street-intrenched trans people who do not have the privileges that I dowhat would the future look like for us all, if we moved beyond the binary?

\section{REFERENCES}

Bueter, A. (2017). Androcentrism, feminism and pluralism in medicine. Topoi, 36(3), 521-530. https://doi.org/ 10.1007/s11245-015-9339-y

Grosz, E. (1994). Volatile bodies: Toward a corporeal feminism. Bloomington, IN: Indiana University Press.

James-Abra, S., Tarasoff, L. A., Green, D., Epstein, R., Anderson, S., Marvel, S., . . Ross, , L. E. (2015). Trans people's experiences with assisted reproduction services: A qualitative study. Human Reproduction, 30(6), 1-10. https://doi.org/10.1093/humrep/dev087
Johnson, A. (2016). Transnormativity: A new concept and its validation through documentary film about transgender men. Sociological Inquiry, 86(4), 465-491. https:/ / doi.org/10.1111/soin.12127

Surkan, K. J. (2013, May). FTM in the fertility clinic: Troubling the gendered boundaries of reproduction. Paper presented at Probing Boundaries of Reproduction: Origins, Bodies, Transitions, Futures, 1st Global Conference, Prague, Czech Republic.

Verlinden, J. (2012). Transgender bodies and male pregnancy: The ethics of radical self -refashioning. In M. M. Hampf \& M. Snyder-Korber (Eds.), Machines: Bodies, genders and technologies (pp. 107-136). Heidelberg, Germany: Universitätsverlag Winter.

von Doussa, H., Power, J., \& Riggs, D. (2015). Imagining parenthood: The possibilities and experiences of parenthood among transgender people. Culture, Health $\mathcal{E}$ Sexuality, 17(9), 1119-1131. https://doi.org/ 10.1080/13691058.2015.1042919

Disclosure. The authors have no relevant financial interest or affiliations with any commercial interests related to the subjects discussed within this article.

Funding. A.J. Lowik's doctoral research is supported by a Social Sciences and Humanities Research Council Joseph Armand Bombardier Canada Graduate Scholarships Program, Doctoral Scholarship.

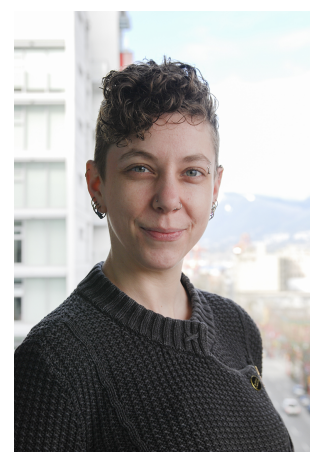

A.J. Lowik (they/them/theirs) is a PhD Candidate with the Institute for Gender, Race, Sexuality and Social Justice at the University of British Columbia. Their research explores all facets of trans people's reproductive lives. They also work at the BC Centre on Substance Use and do freelance trans-inclusion consulting. 